\title{
La libertad sacrificada. La pintura de los Ambulantes en la Rusia prerrevolucionaria
} The freedom sacrificed. Ambulants' painting in prerevolutionary Russia

Rosa Gutiérrez García Universidad Complutense de Madrid (rosagu01@ucm.es)

RESUMEN: La Sociedad de Exposiciones de Arte Ambulante, también denominada "Los Itinerantes" o "Los Vagabundos", se formó en Moscú en 1870 como una agrupación de artistas que buscaba renegar de las normas academicistas de la Escuela de Bellas Artes de San Petersburgo, reclamando la libertad social en detrimento de la libertad artística. En el presente estudio se analiza la transgresión artística ejercida por diversos pintores en el contexto social de la Rusia prerrevolucionaria y cuál fue su repercusión sobre la teoría estética del momento.

PAlABRAS ClAVE: Libertad, Rusia, Pintura de los Ambulantes, Arte social, Arte de la revolución

\begin{abstract}
The Exhibition Society of Traveling Art, also called "The Travelers" or "The Wanderers" was formed in Moscow in 1870 as a group of artists seeking to deny the academic standards of the School of Fine Arts of St. Petersburg, claiming social freedom to the detriment of artistic freedom. The present study analyzes the artistic transgression exercised by different painters in the social context of prerevolutionary Russia and what was its repercussion on the aesthetic theory of the moment.
\end{abstract}

KEYWORDS: Freedom, Russia, Traveling Art Exhibition, Social art, Art of the revolution 


\section{Contexto histórico: evolución diacrónica del caso}

La Rusia prerrevolucionaria abarca desde la segunda mitad del siglo XIX hasta principios del siglo XX, periodo acaecido durante el régimen zarista de los tres últimos emperadores. La evolución de las ideas artísticas como respuesta a los cambios políticos y sociales a finales del siglo XIX alumbraron la corriente artística más representativa del momento, la pintura de los Ambulantes (Peredvízhniki), por constituir una respuesta clara a su precedente; muestran una protesta contra el arte canónico establecido y un acercamiento hacia el pueblo ruso mediante un arte socialmente comprometido.

Desde el año 1613, con la coronación de Mijaíl Fiódorovich Románov, más conocido como Miguel I de Rusia, la dinastía Románov gobernaba en Rusia bajo un régimen zarista. El Zar reunía en su persona todos los poderes (legislativo, político, judicial), y como jefe del ejército y cabeza de la Iglesia Ortodoxa se le rendía un culto quasi divino. Alejandro II ascendió al trono en el año 1856. La difícil situación que vivía Rusia en esos momentos, con la guerra de Crimea y el enorme fracaso que ésta produjo, llevó al Zar al firmar el tratado de París en 1856. La tensión política y social que se palpaba en el país fue incrementándose. El malestar entre el campesinado y las fuerzas crecientes de la intelligentsia ${ }^{1}$ tomaban poder frente al opresivo régimen zarista de su antecesor, el emperador Nicolás I.

El 19 de febrero 1861 se declara la abolición de la servidumbre; un momento decisivo para Rusia en general y para el grupo Ambulante en concreto, pues se está debatiendo un cambio estético decisivo que a partir de este momento tomará dos caminos divergentes: un arte socialmente comprometido o un arte libre. Esta dicotomía cristalizará en asuntos más complejos que veremos más tarde y que tendrán siempre como epicentro la libertad en dos de sus vertientes: la artística y la social. Sin embargo, la ansiada libertad de los campesinos no llegó con la abolición de la servidumbre, (Iovleva, 2006:133), y, de hecho, cuando Alejandro II manifestaba que era "preferible abolirla desde arriba a esperar a que se produjera desde abajo"2 lo que delataba en realidad era un país todavía lejos de la modernización.

A pesar de la aparente libertad que se había otorgado al pueblo mediante la ley de emancipación de los siervos, la reforma no era lo suficientemente holgada para un campesinado formado por veintidós millones y medio de siervos. Aunque podemos considerar a Alejandro II

${ }^{1}$ Del ruso интеллигенция, transliterado como intelliguéntsiya. Se refiere a una colectividad ideológica formada por diversas clases sociales comprometida con la conciencia social de Rusia que tuvieron gran capacidad de movilización de la opinión pública.

${ }^{2}$ Se trata del discurso del zar Alejandro II pronunciado el 30 de marzo de 1861 en Historia del mundo moderno, Cambridge University Press, Barcelona, 1970-1976, p. 272. 
como el más progresista de los zares, "en la práctica lo que continuó prevaleciendo en las tierras rusas fue un laberinto de formas tradicionales de extracción extraeconómica de excedentes, encarnadas en derechos y deberes consuetudinarios" (Anderson, 1979: 356); en otras palabras, la ley todavía contemplaba un amplio margen para que los terratenientes ejercieran el monopolio de poder sobre la elección de tierras para transferir al campesinado, así como las decisiones relativas a su precio.

Por este motivo se sucedieron las rebeliones en muchas áreas, favorecidas por el incesante crecimiento de la población; una situación que distaba mucho de resultar suficiente para liberar al campesinado de la pobreza (Figes, 2010:198). Se trataba, en efecto, del reconocimiento de la autocracia de su progresiva debilidad y de la inestabilidad política en que gobernaban, y aunque resultó una medida insuficiente, sentó las bases tanto el terreno artístico como el social que determinarían el futuro de Rusia (Allenov, 1991:462). La intelligentsia tomó conciencia de su deber y paulatinamente movilizaron la opinión pública. Además, a una sociedad rusa todavía estamental se le sumó un significativo número de raznochintsi que conformaban la nueva clase media.

Los problemas que asediaban a Rusia los resume muy audazmente Belinsky, crítico literario, en la carta enviada a Gógol, dolido por su cambio ideológico tendente al conservadurismo. Fechada en el año 1847, uno de los fragmentos más ilustrativos dice así: (Nabókov, 2009:193)

[...] "Yo creo que es porque conoce profundamente Rusia solo como artista, y no como un pensador, rol que asumió tan malogradamente en su fantástico libro [se refiere a Almas Muertas]. Y no porque no sea una persona pensante, sino porque ya hace tantos años que está acostumbrado a mirar a Rusia desde su maravillosa lejanía, y ya se sabe que nada es más fácil que, desde lejos, ver las cosas tal como nosotros queremos verlas; porque usted en esta maravillosa lejanía vive completamente ajeno a ella, dentro de sí mismo o de un círculo uniforme, construido igual que usted y sin fuerzas para oponerse a su influencia sobre él".

\section{Y prosigue:}

"Por eso usted no ha advertido que Rusia ve su salvación no en el misticismo, no en el ascetismo, no en el pietismo, sino en los logros de la civilización, la instrucción, el humanitarismo. [...] Las más vivas y contemporáneas cuestiones nacionales en Rusia son ahora: la aniquilación del derecho de servidumbre, la supresión del castigo corporal, introducir en lo posible un severo cumplimiento al menos de aquellas leyes que ya existen. Esto lo siente incluso el mismo gobierno (que sabe muy bien lo que hacen los terratenientes con sus campesinos y cuántos de los primeros matan los últimos cada año), lo que se demuestra con sus tímidas e infructuosas semi-medidas en provecho de los negros blancos y el cómico reemplazo del látigo de una punta por el de tres puntas". 


\section{El nacimiento de una idea: el alma rusa en juego}

El círculo académico de mediados del siglo XIX, con la Academia de Bellas Artes de San Petersburgo a la cabeza, se encontraba encorsetado en el pseudoclasicismo de Bruni y Briulov, los dos máximos exponentes y profesores de la Academia, que no admitían la modernidad que se estaba gestando entre los artistas, incluso dentro de la propia corporación. A la vista de tan restrictivo panorama, pues las nuevas teorías estaban absolutamente prohibidas en la Academia, parecía un conflicto inevitable que los nuevos jóvenes pidieran escapar de un género tan manido como la pintura de historia.

Durante la revolución decembrista de 1825 las primeras ideas intelectuales estallaron como la pólvora. El filósofo Pisarev defendió la destrucción de la estética, que cristalizaría un siglo después de forma definitiva. Lenin abogó por la doble vertiente del arte: "El arte pertenece al pueblo. Debe ser comprensible para esas masas y amado por ellas", dirá Lenin a Clara Zetkin. Sin embargo, la relación arte-pueblo no se plantea aquí en términos tan simples como parece: "Para que el arte pueda aproximarse al pueblo y el pueblo al arte, debemos elevar primeramente el nivel cultural general”. (Sánchez, 1970: 8-13). Además, durante todo el siglo XIX todavía tenemos que hablar de un arte gubernamentalmente controlado por Nicolás I, en todas sus formas y variantes, aniquilando cualquier resquicio de sinceridad creativa, consciente como era del poder que encarnaban la imagen y la palabra.

En abril de 1855, El contemporáneo (Современник), un diario en el que participaban activamente demócratas revolucionarios, y en el que se hacía un llamamiento directo a la unión del pueblo, Chernyshevski pudo publicar su célebre tesina, que tenía por nombre Relaciones estéticas del arte con la realidad. El título era muy ilustrativo de sus intenciones y su influencia posterior sobre el grupo de artistas no tendrá parangón en la historia estética rusa del siglo XIX. En su ensayo, el crítico formulaba la tesis del nuevo arte: “el tema es bello porque en sí mismo muestra la vida o nos recuerda a ella." (Iovleva, 2006:132)

A partir de la década de los 60 surgieron los populistas (naródniki), quienes apoyaban un cambio revolucionario basándose en la creencia de que los campesinos constituían una fuerza revolucionaria natural, primordial. La idealización del campesinado como depósito de las virtudes autóctonas que la civilización occidental amenazaba con destruir marcará el paso de una corriente artística bucólico-romántica del mundo rural, a la cruda descripción de un campesinado en situación de grave miseria. 
En este infeliz contexto académico y político, un grupo de catorce jóvenes artistas, con tanta rebeldía como talento, graduados en la Academia, solicitaron al consejo elegir libremente el tema de su pintura para la obtención de la medalla de honor, que de rigor, se entregaba al final de su formación. En 1863, ante la negativa del consejo, considerando la petición una ofensa contra las reglas del mundo académico, el grupo de disidentes renegó de la Academia así como de todos los méritos que podrían haber logrado bajo su seno, y formaron el $\operatorname{Artel}^{3}$ de Artistas de San Petersburgo, la primera agrupación de artistas independientes que, sin embargo, tuvo la corta vida de cuatro años. A pesar de haber cosechado escasos logros artísticos en este tiempo, a finales de los 70 ya se habían constituido como la Sociedad de Exposiciones Ambulantes con la que se les conoció hasta el final de su vida artística. Su lema: La verdad de la vida.

Lo que estaba en juego era la búsqueda del alma rusa, esto es, la ideología de la singularidad nacional que ya había advertido Allenov. Para Chaadev, la única alternativa para restaurarla era "rehacer todo el curso de la experiencia humana" (Vayá, 1989:3); su visión nihilista tenía dos fundamentos de tipo determinista; en su opinión, la geografía y la iglesia bizantina habían distanciado a Rusia de la cultura europea. En realidad, la problemática subyacente que delata la frase se refiere, más que a la posición geográfica de Rusia, a su pertenencia .en el mundo. Si Rusia pertenecía a Oriente o a Occidente constituía el interrogante mayor planteado por ideólogos, artistas, filósofos y políticos, que encontró tantas respuestas como cabezas pudieron concebirlas. Frente a tendencias tanto occidentalizantes como orientalizantes, parecía que los rusos estuvieran en un "fuera del tiempo" (Gatto, 1972:151), algo similar al célebre retiro mágico de Thomas Mann. Su decantamiento ideológico ha de hallarse en 1880 con el descubrimiento del monumento al poeta Pushkin en Moscú, que rápidamente devino encarnación de la esencia nacional. Al mismo tiempo, Dostoievsky volvía a ser reconsiderado por los estudiantes de Moscú y en los años 90 Rusia ya había recuperado definitivamente el idealismo trascendental de Kant. Recordemos que en tiempos peores el poeta Pushkin había sido calificado de ignorante por la Iglesia y un joven Dostoievski había sufrido destierro por parte del gobierno.

\section{La independecia de los ambulantes y el llamamiento a los vivos}

En la década de los 70, los Ambulantes se habían constituido como una nueva asociación dispuesta a organizar exposiciones itinerantes fuera de las grandes ciudades. En total se celebraron un total de 48 exposiciones que buscaban propagar el arte por todo el Imperio. Las razones también eran 
económicas: la necesidad de liberarse de los controles burocráticos de San Petersburgo con el objetivo de constituir un mercado propio, ateniéndose a las normas sociales de su Artel. Prácticamente, todos los grandes artistas de la segunda mitad del siglo pertenecieron en algún momento a los Ambulantes. Bajo los ideales cívicos y populistas de la década anterior, recorrían las provincias con sus exposiciones para acercar, según decían, el arte al pueblo.

El papel del zarismo y de la alta nobleza en la financiación de los nuevos círculos artísticos resulta especialmente significativa al respecto. Podría resultar contradictorio que las clases altas ejercieran el mecenazgo de obras creadas ex profeso para las clases más bajas; en el caso del cuadro Sirgadores del Volga de Ilia Repin, el duque Vladimir Alexandrovich, el hijo más joven del zar, fue quien encargó la obra y llegó a invitar a los hambrientos campesinos que había retratado el pintor, tomando apuntes del natural, en su suntuoso comedor (Figes, 2010: 297). Con todo, el mayor filántropo del grupo Ambulante había sido, sin duda, el controvertido mecenas Pável Tretiakov (1832-1898), que logró aunar la mayor colección de arte realista-crítico del momento. A partir de los años 20 se produjo una transformación de la clase que detentaba la cultura, -antes monopolizada en manos de la nobleza- lo que causó un traspaso, aunque limitado y parcial, de ésta, a nuevas clases. Los Ambulantes vivieron de forma ambivalente el hecho de que fueran financiado por las élites que ellos habían rechazado, y no deseaban subordinarse artísticamente. Sin embargo, la libertad total del arte ha sido una utopía durante prácticamente toda la historia; o bien queda subsumida por las reglas dictadas por el mercado, o bien por los vínculos que unen a los artistas con determinados sectores de la sociedad. (Bourdieu, 1995: 490)

En ese camino gradual que siguieron los artistas, la pintura realista aún se hallaba en un período de transición frente a los conflictos sociales de la Rusia del siglo XIX. La pintura de la segunda mitad del siglo todavía estaba atravesada por una "estructura del sentimiento" (Raymond, 1997:156-157) donde se combinaban elementos en una dialéctica tensional evidente: los románticos de un lado y realistas por el otro (Caspasso, Hang, 2010:6-8). El alejamiento del romanticismo aún no estaba delimitado del todo, y esto produjo la aparición de obras que dan ejemplo de ese período de transición, tanto en forma como en contenido.

Kramskói sienta las bases teóricas del grupo. Estamos viendo que la nueva concepción del arte se movía en términos de compromiso con la realidad. El debate de la época oscilaba entre dos posturas, el arte por el arte o la creación de un arte socialmente comprometido. Para los Ambulantes, el decantamiento ideológico era claro: "el espíritu y el contenido del arte reclaman un mayor campo de acción” (Marcadé, 1971:51). Concebían el arte precisamente como eso, como el mejor escenario en el que denunciar las carencias de la estructura social. El deber social establecido 
de forma prioritaria desplazó el fin estético a un segundo plano y tuvo una plasmación literaria ostensible en la famosa publicación Kolokol (Колокол, сатрапа), una revista literaria fundada у editada por Herzen, que tenía por lema Vivos voco (Convoco a los vivos). Se trataba de un llamamiento directo al pueblo, al campesinado que había vivido en el ostracismo, pero no sólo eso; se convocaba al despertar de la conciencia social rusa con una campana que resonase, como dijo el propio Herzen, en el interior de cada hombre.

La caída de la servidumbre había provocado la aparición de los raznochintsi, los representantes cultos de la burguesía liberal, normalmente formado por estudiantes, profesores y otros intelectuales que no pertenecían a la nobleza. "Los raznochintsi ascendieron hacia la luz del día; sin ella no habrían podido existir" (Malia, 1961:13). Estamos ante la transición, dura y paulatina del feudalismo al socialismo, a través de la etapa capitalista; el papel de la crítica social, que avanza desde los decembristas a los comunistas sería expresión de los intereses de la baja burguesía, y por extensión, del campesinado como la clase democrática. La intención ulterior era la realización de una revolución demócrata (Calatrava, Davidenko, 2000:13) convertida en vanguardia social. Cabe interrogarse sobre la concepción del arte con arreglo a esta actitud socio-política.

\section{4. "La destrucción de la estética". el desplazamiento de la libertad}

La tesis de Pisarev sobre la destrucción de la estética hemos de entenderla en el contexto de la necesidad del artista de servir a su pueblo. El arte no era entendido de manera finalista, sino como un medio que poseía una utilidad social, que siempre y en todo caso debía ser de orden moral. La denominada "estética de lo útil" no dejó de ser un eslogan de moda que inundó el pensamiento y la temática de los artistas de la década. Su radicalismo progresista desplazó toda búsqueda de belleza en detrimento del fin social. Oponiéndose a la visión del arte como fin per se, Pisarev escribió La destrucción de la estética (1865) donde investigó la utilidad del arte al servicio del pueblo, renegando de cualquier acto creativo que no se atuviese a un fin social; sus planteamientos eran similares a los del socialista utópico Chernyshevski, quien dijo: "la tarea del arte consiste, no solo en reflejar la realidad, sino en dictarle a ésta su veredicto" (Marcadé, 1971:27). En definitiva, para Pisarev el arte debía constituir lo opuesto al hedonismo, debía negar la búsqueda del placer, pues este resultaba infructuoso y frívolo, y por supuesto, al arte debía guiarle una misión moral.

La visión artística del Tólstoi no separa tampoco la belleza de su cualidad moral, sin embargo sí trasciende las ideas de Pisarev, que por extremas resultan limitadas, afirmando que el arte nace como un medio de comunicación entre los hombres y limitar su definición al placer sería 
constreñirlo, sin embargo, no niega que el fin del arte es el placer, si bien "este placer debe ser eminentemente moral." (Tólstoi, 2007:15).

A esta cuestión se responde como sigue (Trevijano, 2002: 22):

"La sinceridad que importa en el arte, sea literario o plástico, es la de la obra, no la del autor. En esto, la teoría estética de Tólstoi, no la de Ana Karenina, se equivoca. La expresividad tampoco es una cualidad que distinga al talento razonador o al seductor. Pues toda obra de acción, de pensamiento y de arte es expresiva de lo propio y de lo común donde se origina. Incluso de la idiotez y la rudeza."

Krámskoi buscaba independizarse del yugo de la academia; rechaza tanto la herencia artística rusa academicista como las influencias extranjeras, las cuales sí adoptaron otra agrupación de pintores e intelecuales rusos, los de la revista El mundo del arte (Mir iskusstva, 1898). Esta agrupación, formada por artistas, filósofos, escritores e intelectuales, constituía una completa oposición a los Ambulantes y a todo movimiento realista precedente. La voluntad artística de Mir iskusstva reposaba en una vuelta a lo bello, a lo clásico, con lecciones tomadas del Impresionismo europeo. Para los Ambulantes no se debían crear obras vacías de contenido social, aunque para ello hubiese que negar la belleza, mientras que para los de Mir iskusstva la única fuente verdadera de belleza era el arte mismo en tanto que éste derivaba por excelencia del campo de lo bello. Sin embargo, en esta agrupación del Mundo del arte se unían contradicciones que llevaron al movimiento a la decadencia, aunque no es nuestra misión analizarlas en el presente estudio.

El Ambulante Krámskoi pone la atención sobre la mirada de los campesinos; no es que estos artistas renegasen de la pintura de género como tal, cuyos antecedentes hemos de buscarlos en Venétsianov (1780-1847) y Fédotov (1815-1852), pero sus visiones resultaban idealizantes, poetizantes, bucólico-románticas, y en opinión de los Ambulantes, tergiversaban la realidad del pueblo, y el arte debía constituir un auténtico "manual para la vida", como ya había señalado el revolucionario Krámskoi. Si observamos Los Segadores de Venétsianov (finales de 1820) en opinión de Vayá es el paradigma de la acuñación de "la imagen poética del aldeano ruso". (Vayá, 1989:6) Bien es cierto que lo que hizo Krámskoi no tenía precedentes en el arte ruso; en Campesino con una brida [1] no solo centra la atención en el rostro del trabajador, en vez de hacer que éste aparezca de forma secundaria en un plano abierto o desarrollando una actividad al fondo, sino que lo trae al primer plano y le dota de tal concentración psicológica que el espectador lograba ser consciente de que tenía ante sí, por primera vez, el mundo interior de personas a las que nunca se las había tratado como humanos. No estamos ante una moralización de una clase social, tal y como ocurre con Millet, sino de una progresiva humanización de la misma. 


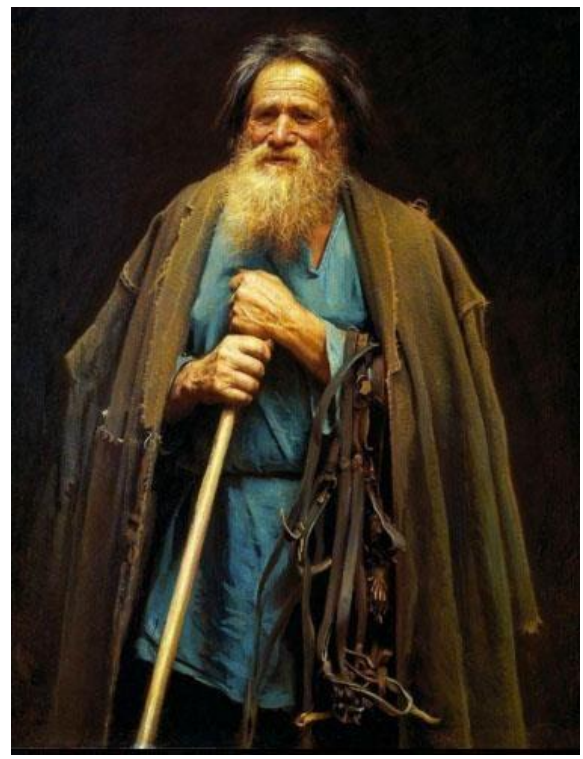

1. Kramskoi, Campesino con una brida, 1833. Museo Nacional de Arte de Ucrania @

Uno de los más relevantes compromisos de los Ambulantes fue la pintura de paisaje. En realidad, el proceso que se vive en Occidente con su paulatino protagonismo a partir del siglo XVII se debe a motivos diametralmente opuestos a los del caso ruso. En Europa, la pintura de paisaje proclama la necesidad de un arte alejado de la narratividad con el objetivo de afirmar la ingenuidad de la pintura. En Rusia, la supremacía del género paisajístico respondía a su ansiada búsqueda de la identidad nacional, pues en el paisaje se veía la vida de la gente. Digamos que los Ambulantes reconocían en el paisaje la naturaleza íntima en relación con la vida íntima de la gente. La pintura Ambulante tiende hacia lo narrativo cuando se aleja de la pintura canónica establecida y la pintura europea tiende a la desliteraturización. La carta que Ilya Repin manda a la revista Mir iskusstva es sintomática de este hecho: "Si Monet llegase alguna vez con sus amarillos y sus lilas a obtener el efecto del Diluvio de Aivazovski, lo elevaría sobre el pavés”. (Reau, 1957:185)

Aivazovski, el pintor del Mar Negro, unió la veracidad de la realidad del paisaje con la visión romántica del mundo, desmintiendo que eran contradictorias. La pintura de Fédotov es realista en tanto en cuanto pretende mostrar los vicios sociales para ayudar a superarlos, y en este sentido podríamos decir que adquiere un cariz moral, casi pedagógico, pero se mantiene todavía en términos idealizantes que impiden en el espectador un verdadero choque psicológico ante la verdad de la realidad. No ocurre lo mismo con Vasili Grigórievich Perov, miembro y co-fundador de la Sociedad de Ambulantes, cuya imagen ha resultado ambivalente, pues se decía que la pintura de Krámskoi era más realista-crítica, y por tanto socialmente más pura, debido a su rechazo a las 
influencias extranjeras; si bien no podemos negar el estudio de Perov de las obras francesas (Courbet, Millet), así como sus sucesivas estancias en París, pues eran muchos los autores Ambulantes que viajaron por toda Europa e incluso llegaron a exponer en salones parisinos.

Para Ilya Repin, la mayor figura del realismo ruso, la belleza estaba unida necesariamente a la verdad. "En la verdad está para mí toda belleza" (Aiguabella,1987), dirá; esa verdad ha de ser entendida en términos sociales, pues tomaba tanto temas de la actualidad contemporánea, como es la soberbia composición de Los sirgadores del Volga (1872) [2], como temas de la historia rusa sin ningún pudor interpretativo.

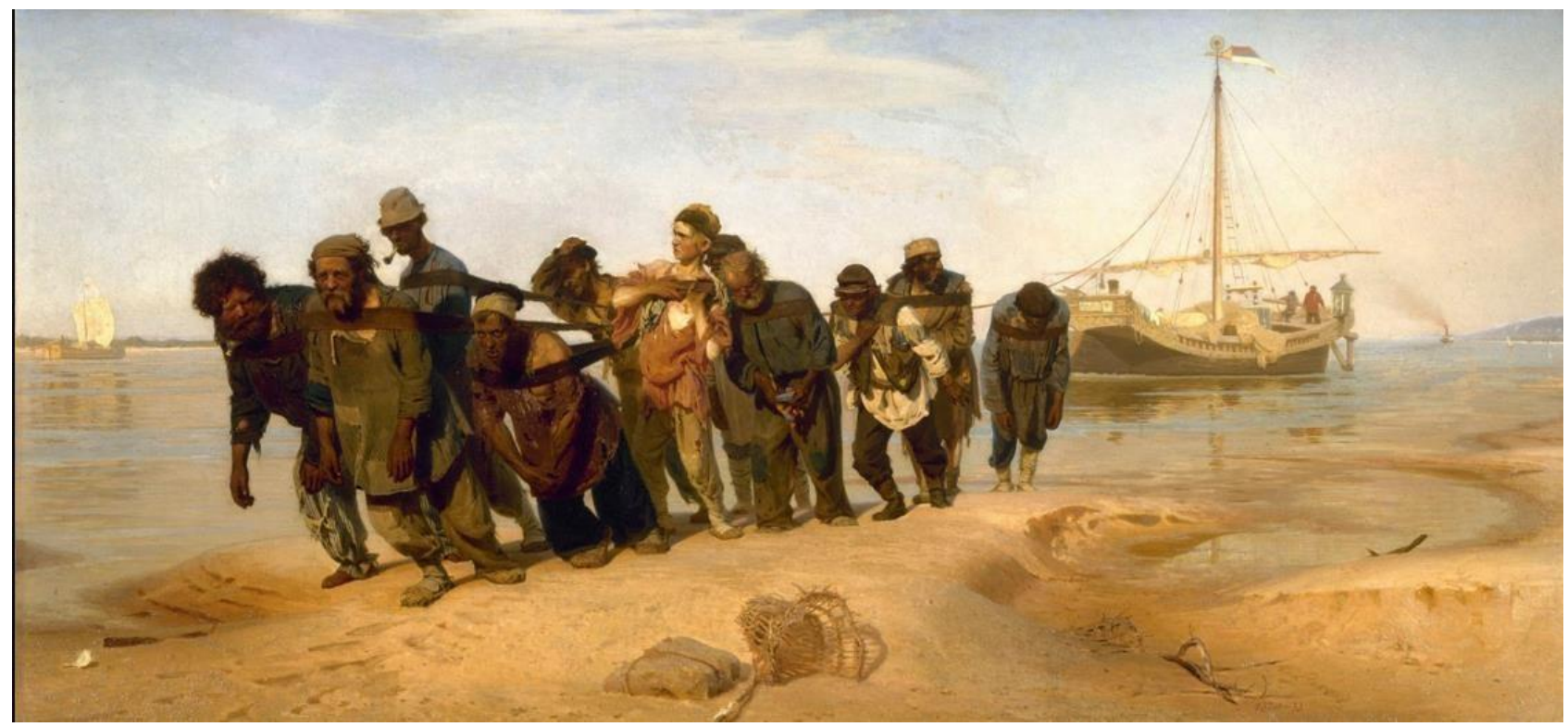

2. Ilya Repin, Los sirgadores del Volga, 1870-1873. Museo Estatal Ruso @

Es el caso de Iván el terrible y su hijo (1885), relata el episodio acaecido el 16 de noviembre de 1581 en el que el zar Iván IV asesinó a su primogénito en un acceso de ira. La esposa del zarévich, Elena Glinskaya, estaba encinta y el zar la había golpeado por considerar que iba vestida de forma indecente. El zarévich se enfrentó a su padre, que le asestó un golpe mortal y definitivo con su cetro. Era su hijo predilecto. El estudio de la culpa en los ojos expresivos del zar, y la inevitabilidad de la muerte en una rica estancia, consagran a Ilya Repin como uno de los mejores pintores de todos los tiempos. La pintura costumbrista, el género más representado por los Ambulantes, resultó ser fiel reflejo de la idea nacional en tanto que se representaba de forma veraz la dura vida de los campesinos, esencia de la ruseidad por excelencia. Así, mientras pintaba Los 
Sirgadores del Volga dijo "los mujik $k^{4}$ son ahora jueces y por tanto hay que reflejar sus intereses", (Iovleva, 2006: 133)

\section{La libertad artística a debate}

El arte se encaminaba hacia la verdad y la verdad caminaba hacia el pueblo. Esta concepción del arte como un instrumento de utilidad social nacía de la incansable búsqueda por hallar cuantas respuestas encerraba el devenir de un país que comenzaba a despertar de su larguísimo letargo. La búsqueda de la identidad propia en el pueblo, que encarnaba para los artistas el alma rusa, significaba también una lucha incansable por la libertad, entendida en términos de progreso social. En el terreno del arte se había logrado una paulatina liberación de los grandes géneros que habían legitimado hasta entonces su pintura y, una vez comprobado que el talento artístico de los Ambulantes, así como de las nuevas corrientes artísticas, no podía someterse a normativas canónicas de escuelas, se fundaron nuevas que dictasen nuevas normas, amparadas en otras esperanzas. La necesidad de producir un efecto útil en una sociedad huérfana fue el faro que les encaminó a puerto.

La libertad artística estaba en el centro de todas las discusiones. Si lo determinante era la razón social del arte, no cabía la libertad artística; parecían dos cuestiones contradictorias que sin embargo acabaron por resolverse de la mejor manera. La libertad artística era un precio muy bajo a pagar, teniendo en cuenta que estaba sometida a las normas canónicas de la Academia de Bellas Artes de San Petersburgo, y cuando dejaron de estar ancladas en estos términos, se convirtieron en esclavas de la verdad. La primera norma de los Ambulantes fue renegar de la búsqueda de la belleza, o buscarla, si acaso, en la verdad de la vida. Pero una cosa es la socialización del arte y otra cosa es un arte social. Por los mismos motivos, no es lo mismo un arte revolucionario que un arte de la revolución. No creo, como Adolfo Vázquez, que "el arte en la revolución se dé como revolución en el arte”. (Sánchez, 1970:8) La socialización de la belleza, que normalmente corresponde a una misión de los medios de comunicación para acercar al pueblo el arte, -y este arte no tiene por qué ser necesariamente social- aquí correspondió a los Ambulantes, cuyas exposiciones itinerantes propagaban sus ideas socio-artísticas por todo el imperio ruso. La socialización de la belleza, por tanto, responde a la difusión del arte en tanto que propagación al mundo, mientras que el arte socialista, en este caso está ligado a una ideología política que hemos visto alumbrada en el contexto de la Rusia prerrevolucionaria. En otras palabras, "el arte socialista 
sustituyó la obra estética del arte expresivo de belleza, por la obra ética expresiva de un mundo mejor". (Trevijano, 2003: 90)

La pretensión de sustituir la estética por una ideología, en este caso de corte socialista, podría haber sido nefasta, y si bien el valor de la imagen para los Ambulantes no se medía por su calidad estética, nadie puede negar que la tuvo. Este movimiento confirma la tesis de que la belleza no siempre llega con su búsqueda, y en ocasiones, aunque el artista la rechace en su corazón, la encuentra su talento.

La razón de esta feliz casualidad se debe a lo que aquí hemos denominado "libertad desplazada"; se trata de un fenómeno por el cual el artista, que no puede negar el compromiso de su vida política, se convierte en un ideólogo de formas y mediante la autoprohibición de su autonomía creativa en pos de su libertad intelectual, es capaz de alumbrar otra libertad artística inherente a su capacidad creativa. Es decir, que los Ambulantes quisieron inaugurar un arte de la revolución política pero hallaron un arte estéticamente revolucionario. Ello no significa, como señala Trevijano, que "el estilo sea indiferente a la ideología del artista", (Trevijano, 2003: 86) pues el modo de decir algo, en este caso, la denuncia de la servidumbre, corresponde por lo general al sentimiento que la despierta; un modo de decir realista para una realidad que necesitaba una representación lo más veraz posible, alumbró un tipo de belleza universal que puede ser disfrutada a pesar de su nacimiento en el seno de lo puramente político. "Que sea como un charco sucio si en ello está la verdad”, dirá Tetriakov. Representaron la fealdad del mundo con belleza, y la capacidad psicológica del realismo de los Ambulantes trascendió cualquier intención política confirmando la tesis de que todo gran arte trasciende la pasión primaria en que está inspirado: (Trevijano, 2003: 90)

"Si la obra expresa algo inédito que la sociedad ignora o rechaza, cuando ésta lo descubre y admira se produce un doble reconocimiento de naturaleza social. La obra devuelve a la sociedad lo que el artista, aún el de genio más autónomo, tomó de ella en el momento creador. Pues no puede haber nada en su inspiración que no proceda de la experiencia de su vida personal en la Naturaleza y en la humanidad. Y la sociedad devuelve a la obra el sentido humano de la belleza solitaria que encerraba mientras permaneció escondida o incomprendida, haciéndola social. La necesidad de este doble reconocimiento explica que todas las obras geniales, incluso las originariamente comprendidas, no pertenezcan la época donde nacieron y que cada generación las complete, sin agotar nunca el sentido universal de su expresión". 


\section{Referencias bibliográficas}

AIGUABELLA, Javier (1987). Pintores rusos del siglo XIX: del Neoclasicismo a la Revolución, marzo/junio 1987, en Cat. Expo. Museo del Prado, Palacio de Villahermosa: Madrid.

ANDERSON, Perry (1979). El estado absolutista. Siglo veintuno: España

ALLENOV, Mikhail (1991). L'Art Russe. París, Citadelles: Francia.

BELINSKI, Visarión (1956). Selected Philosophical Works, Foreign Languages Publishing House: Moscú.

BOURDIEU, Pierre (1995). Las reglas del arte. Anagrama: Barcelona.

CALATRAVA, J.Vallés, DAVIDENKO, Marina (2000). Crítica social realista rusa, (vol II), Universidad de Almería: España.

CAPASSO, Verónica; HANG, Julia (2010). “Arte y sociedad: Rusia y la pugna entre lo viejo y lo nuevo", en II Congreso Iberoamericano de Investigación Artística y Proyectual. Universidad Nacional de la Plata: Argentina.

FIGES, Orlando (2010). El baile de Natacha: una historia cultura rusa. Edhasa: Barcelona.

GATTO, E. L (1972). La literatura rusa moderna. Losada: Buenos Aires.

GATTO, E.L (1925). Critici letterari russi. A cura. Franco Campitelli: Foligno.

MALIA, Martin (1961). Alexander Herzen and the birth of Russian socialism, 1812-1855.

Cambridge, Mass, Harvard University Press: Reino Unido.

MARCADÉ, Valentine (1971). Le renouveau de l'art pictural russe 1863-1914. Lausana: Suiza.

NABÓKOV, Vladimir (2009). Curso de Literatura Rusa. Zeta: Barcelona.

NÓVIKOVA, Olga (1997). Rusia y Occidente (Antología de textos). Tecnos: Madrid.

RÉAU, Louis (1973). El arte ruso. Fondo de Cultura Económica: México

SÁNCHEZ, Adolfo (1970). "Notas sobre Lenin, el arte y la revolución”, en Revista de la Universidad de México, vol. 25, nº 3, pp. 8-13.

TOLSTÓI, León (2012). ¿Qué es el arte? Maxtor: España.

TREVIJANO, Antonio (2002-2003). “Arte”, en La Razón, pp. 5-95 [Disponible online].

IOVLEVA, Lidia (2006). "El arte ruso de la segunda mitad del siglo XIX: los Ambulantes. Pavel Teatriakov y su galería”, en Cat. Expo. ¡Rusia!: novecientos años de obras maestras y colecciones 
magistrales:/[Biillington; Vzdornov... et al.] Bilbao, España: Guggenheim Bilbao Museoa, D.L. pp. 132- 139 .

VAYÁ, Esther (1989). "El Realismo crítico-social ruso: La Sociedad de Exposiciones Ambulantes" en Saitabi, pp. 1-11.

VV.AA (1970-1976). Historia del mundo moderno. Barcelona, España: Cambridge University Press.

WILLIAMS, Raymond. (1997). Marxismo y literatura. Barcelona, España: Península. 